\title{
The Quality of Newborn Data: Assessment of Data Management and Reporting System
}

\author{
Emmanuel Kusi Achampong ${ }^{1}$, Godwin Adzakpah², Richard Okyere Boadu ${ }^{3}$, \\ Obed Owumbornyi Lasim ${ }^{4}$ \\ ${ }^{1}$ Department of Medical Education and IT, School of Medical Sciences, University of Cape Coast, Ghana \\ ${ }^{2,3,4}$ Department of Health Information Management, School of Allied Health Sciences, University of Cape Coast, Ghana
}

\section{Article Info}

Article history:

Received Jun 17, 2018

Revised Sep 5, 2018

Accepted Sep 15, 2018

\section{Keyword:}

Health information system

Monitoring and evaluation

Newborn data

Quality

\begin{abstract}
Data quality assurance through the district, regional and national health information systems is a sure way of having a meaningful interpretation, but this is a challenge in many developing countries. The purpose of this study was to determine the availability and data completeness of key newborn data indicators collected at the health facilities and to determine the use of newborn data for planning and decision-making at the Cape Coast metropolis. The study was a descriptive qualitative assessment. An in-depth interview was conducted in four hospitals within the Cape Coast Metropolis. There were unique best practices identified with some hospitals such as staff distribution and utilization in data collection and reporting, using data for decision making, and to define newborn indicators, data collections tools and the processes involved in data management and utilising supportive supervision from both the region and district levels. In order to sustain health information management, fundamental monitoring and evaluation issues, standardisation of monitoring and evaluation practices in data and information management must be addressed. In addition, investment should be made into the adoption of electronic medical records systems and tertiary training programs to support monitoring and evaluation activities in the hospital.
\end{abstract}

Copyright (c) 2018 Institute of Advanced Engineering and Science. All rights reserved.

Corresponding Author:

Emmanuel Kusi Achampong,

Department of Medical Education and IT

School of Medical Sciences

University of Cape Coast, Cape Coast, Ghana.

Email: eachampong@ucc.edu.gh

\section{INTRODUCTION}

An inadequately skilled health workforce have been identified as part of the factors that contributes to poor health outcomes in developing countries, including Ghana [1]. Even though the spotlight has been on nursing and medical personnel, the performance of the health system as well as the health information system generally goes beyond these types of health professionals [2]. All health professionals must generally be involved in the data collection and data quality processes.

Routine health information generated at healthcare facilities are important for assessing the performance of health systems [3]. An active routine health information system (RHIS) relies on the availability as well as use of data from healthcare institutions [3]. The use of these data would help monitor the status of the healthcare system. These data will also help proffer evidence-based solutions that has the potential to improve health services quality and eventually affect health outcomes for patients and the population in general [4]. Most data for decision making and planning emanate from the health facilities. Data quality depends on the knowledge and skills of professionals who are responsible for these data [5]. 
The skills of healthcare professionals who are involved in the data collection process must be enhanced. The quality of newborn health data mainly depends on the staff at the respective departments and the health information department/unit. Tools and methods are needed for monitoring the quality of newborn health data at healthcare facilities. The purpose of this study was to determine the availability of key newborn indicators collected at the health facilities, to determine the standardization of tools used to capture institutional newborn data at the health facilities and to determine the use of newborn data for planning and decision-making at the Cape Coast metropolis.

\section{RESEARCH METHOD}

The study was conducted in the Central Region of Ghana. The research was undertaken in four health facilities. Assessment was conducted through in-depth interviews within the selected health facilities in the Cape Coast Metropolis. MEASURE Evaluation's Routine Data Quality Assessment Tool was adapted to guide interviews. The assessment focused on six thematic areas of data management and reporting systems. The interview was recorded and transcribed with permission from each interviewee. NVivo 10 software was used to analyse the data. The newborn health data assessed includes; total number of births, total number of livebirths, total number of fresh stillbirths, total number of macerated stillbirths and total number of institutional neonatal deaths. Probability and purposive sampling methods were employed in this study. The health facilities in the metropolis were put into two strata: private and public health facilities. Out of the three public hospitals, simple random sampling method was used to select two (2) for the study. Purposive sampling method was used to select the two (2) private hospitals in the Metropolis which provides antenatal care (ANC), deliveries and newborn care services. Further, purposive sampling method was used to interview key staff who were involved in newborn care and data management at the hospitals and were available at the time of the assessment period.

\section{RESULTS}

\subsection{Review of Source Documents}

The research reviewed three source documents namely: documents availability, documents completeness and documents within reporting periods for the six indicators of newborn health data (i.e. total number of births, total number of livebirths, fresh stillbirths, macerated stillbirths, neonatal deaths and number of babies referred to the facility) selected for study. Documents availability means that all indicator source documents for the period of reporting were available for review. The study shows that there were $100 \%$ source documents available for capturing total number of births, and total number of livebirths whilst fresh stillbirths, macerated stillbirths, neonatal deaths and number of babies referred to the facility show 50\% availability.

Documents completeness means that there is a value recorded when there should be one, or no missing data. The study revealed that the documents available were $75 \%$ complete for total number of births and total number of livebirths and 50\% complete for total number of fresh stillbirths, macerated stillbirths, and neonatal deaths and $25 \%$ complete for total number of babies referred to the facility. Documents within reporting period means that the documents were current, and the information were available on time per standard operating procedures (SOPs). The study revealed that $75 \%$ of documents (i.e. total number of births, total number of livebirths) were within reporting period. Fifty percent (50\%) for fresh stillbirths and macerated stillbirths whilst $25 \%$ of neonatal deaths and number of babies referred to the facility under review were complete within the reporting period (January 2015 to December 2016) shown in Table 1. 


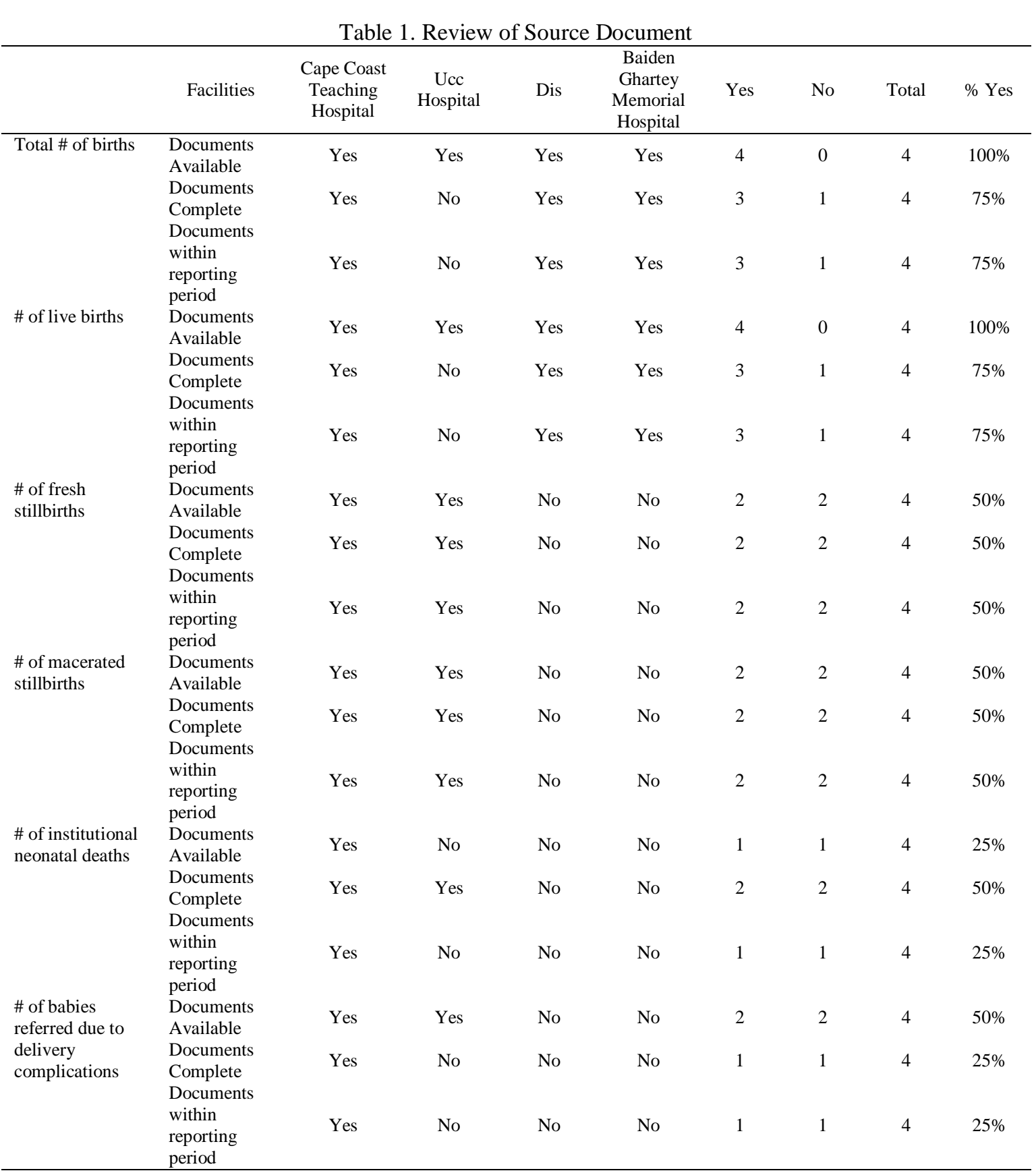

\subsection{System Assessment}

\subsubsection{Monitoring and Evaluation (M\&E) Structures, Functions, and Capabilities}

The study revealed that there were defined key monitoring and evaluation and data management responsibilities at the hospital with a total score of 2.69 representing $89.7 \%$ score shown in Figure 1 and Table 2. The findings revealed that there were staff who sole responsibility was to review periodic reports before they were submitted to the next level. In the absence of the responsible staff, there was a system in place that ensures data collection and reporting was still completed. The results can be found in Figure 1. However, training of staff on data management processes and tools were limited. All the training was acquired through workshops by only few leading staffs since there is no tertiary programme on monitoring and evaluation. Midwives did not consider data collection as part their core responsibility. One of the interviewee remarked:

"Poor documentation and ineligible handwriting from the maternity makes data to be of low quality". 
The national and district level staff rarely visited the facilities to provide training as stipulated in the guidelines. One of the interviewee remarked:

"Midwives said they receive less supervision".

\subsubsection{Indicator Definitions and Reporting Guidelines}

Indicator definitions and reporting guidelines had a total score of 1.88 representing $62.7 \%$ shown in Figure 1. The study revealed that there was no available or written guidance on indicator definitions at the maternity ward. The study revealed mixed responses concerning the existence and availability of indicator definitions, with some respondents indicating that these were available but were not shared with other users. Others indicated that they do not have these definitions. Some of the conflicting responses are presented below

"Yes, in the guidelines there are definitions that guide us on specific indicator and how it should be collected. No, there are no guidelines available at the maternity, but a copy might be at the biostatistics office”.

"I got to know only at workshops and training".

Knowledge of reporting deadlines seem to be communicated verbally but not documented as remarked by one of the interviewees;

"We have been prompted verbally on the reporting requirements and deadlines but don't have any written document to that”.

\subsubsection{Data Collection and Reporting Forms and Tools}

Data collection and reporting forms and tools recorded a total score of 2.42 representing $80.7 \%$ shown in Figure 1. Standardized data collection and reporting forms and tools (Midwifery Form A) were available at some of the facilities and were, generally, reported to be used by the midwives. When these reporting forms and tools did not exist, or were out-of-stock, midwives would, however, request a print out from the biostatistics office. Some facilities have to rely solely on the district health administration office for the supply of these reporting forms. Some interviewees remarked:

"We always have to chase the District for forms/tools for capturing aggregated data and sometimes exempted from the distribution".

"We have no forms/tools for capturing aggregated data and no printer at the department for printing the documents".

On whether the facility has a copy of instructions for the filling of the data collection and reporting forms, the midwives said they did not have instructions with respect to the completion of the data collection and reporting forms. Below is a remarked by one interviewee:

"There are no clear instructions on the completion of data collection and reporting forms/tools at the maternity ward".

Reporting tools were mostly available. Nevertheless, staff complained that these tools changes frequently which makes data completeness a challenge.

\subsubsection{Data Management Processes}

The study revealed data management processes were in the facility with a high score of 2.72 representing 90.7\% shown in Figure 1. The hospital routinely creates back-up files of data on daily basis. Adequate archives of files are also maintained in a clean, dry, with sufficient space. However, some hospitals do not have quality control measures in place for data compilation as well as monthly facility report to ensure data accuracy. They also have inadequate space to maintain reports/documents. There is also no written policy on the duration for retaining source documents and reporting forms. A respondent remarked;

"I have not seen any policy document on the retention of documents since I was engaged" 


\subsubsection{Links with the National Reporting System}

Data generated at the hospital are sent to the district and then to the national level through the webbased district health information management system (DHIMS II) software. The link with the national reporting systems scored a high mark of 3.0 representing $100 \%$ shown in Figure 1 . The study revealed that the relevant national forms were used for both data collection and reporting. The facilities also indicated that data are reported through the DHIMS II. The systems records information about where the services is delivered.

\subsubsection{Use of Data for Decision Making}

It was evident that the hospital use data for decision making as charts, graphs were developed for the indicators under review. These charts and graphs were done on quarterly by assigned staff (i.e. Biostatistics Officer). Use of data for decision making also had a high score of 2.57 representing $85.7 \%$ shown in Figure 1. The study revealed that staff had access to guidance or technical assistance on data use through peer review meetings. It was also evident that the analysed data or results were presented to stakeholders in a timely manner so as to inform decision making. However, some facilities revealed that there was no assigned staff to interpret and analyse the data or result. Table 2 the findings revealed that there were staff who sole responsibility was to review periodic reports before they were submitted to the next level. In the absence of the responsible staff, there was a system in place that ensures data collection and reporting was still completed.

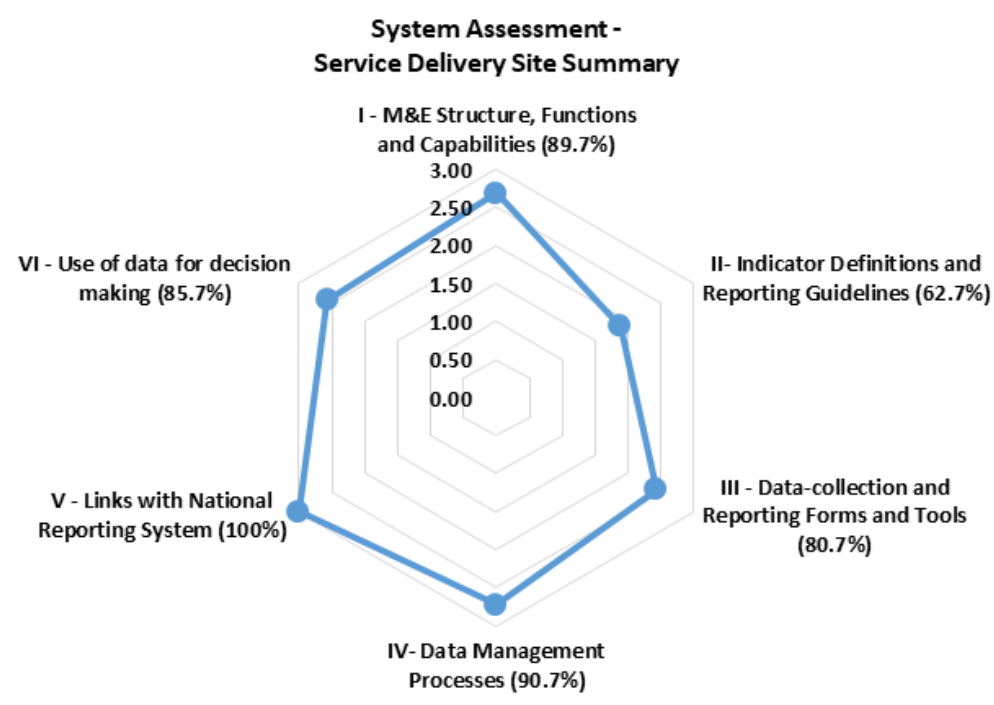

Figure 1. System assessment

Table 2. System Assessment

\begin{tabular}{|c|c|c|c|c|c|c|c|}
\hline Facilities & $\begin{array}{c}\text { I-M\&E } \\
\text { Structure, } \\
\text { Functions } \\
\text { and } \\
\text { Capabilities }\end{array}$ & $\begin{array}{c}\text { II-Indicator } \\
\text { Definitions } \\
\quad \text { and } \\
\text { Reporting } \\
\text { Guidelines }\end{array}$ & $\begin{array}{l}\text { III-Data- } \\
\text { collection } \\
\text { and } \\
\text { Reporting } \\
\text { Forms and } \\
\text { Tools }\end{array}$ & $\begin{array}{c}\text { IV-Data } \\
\text { Management } \\
\text { Processes }\end{array}$ & $\begin{array}{l}\text { V-Links with } \\
\text { National } \\
\text { Reporting } \\
\text { System }\end{array}$ & $\begin{array}{l}\text { VI-Use of } \\
\text { data for } \\
\text { decision } \\
\text { making }\end{array}$ & $\begin{array}{l}\text { Facility } \\
\text { Average }\end{array}$ \\
\hline $\begin{array}{l}\text { Cape Coast Teaching } \\
\text { Hospital }\end{array}$ & 2.33 & 1.00 & 2.67 & 2.78 & 3.00 & 3.00 & 2.46 \\
\hline UCC Hospital & 2.43 & 2.50 & 2.33 & 2.33 & 3.00 & 3.00 & 2.60 \\
\hline DIS Clinic & 3.00 & 1.00 & 2.00 & 2.78 & 3.00 & 1.29 & 2.18 \\
\hline $\begin{array}{l}\text { Baiden Ghartey } \\
\text { Memorial Hospital }\end{array}$ & 3.00 & 3.00 & 2.67 & 3.00 & 3.00 & 3.00 & 2.95 \\
\hline Facility Average & 2.69 & 1.88 & 2.42 & 2.72 & 3.00 & 2.57 & 2.55 \\
\hline Facility Performance (\%) & $89.7 \%$ & $62.7 \%$ & $80.7 \%$ & $90.7 \%$ & $100.0 \%$ & $85.7 \%$ & $85.0 \%$ \\
\hline
\end{tabular}




\section{DISCUSSION}

Quality health data is essential to ensure the proper use of collected data for planning and decision making. A study carried out in Ghana on health information systems, argues that quality data must be in place to reduce clinical and medical errors [6]. Since quality data affects greatly the decision-making process, it is important to ensure that the data collection process is smooth with minimal challenges. About hundred (100) countries collect vital registration data on stillbirths, but only about fifty (50) have high qualityz data [7]. Developing a good data capture, transmission and providing feedback systems will strengthen health delivery services by improving the quality of information used to plan and take right decisions at the national, regional, district, and facility levels.

The availability of documents with respect to the total number of births and number of live births was $100 \%$ whilst documents completeness and documents within reporting period was $75 \%$ respectively. Documents availability, documents completeness and documents within reporting period declines significantly for number of fresh stillbirths $(50 \%, 50 \%$ and $50 \%)$, number of macerated stillbirths $(50 \%, 50 \%$ and $50 \%)$, number of institutional neonatal deaths $(50 \%, 50 \%$ and $25 \%)$ and number of babies referred due to delivery complications $(50 \%, 25 \%$ and $25 \%)$. Thus, documents availability, completeness and documents within reporting period declined significantly across all the facilities when there were deaths involved. A study in Mozambique which assessed primary care health data find out that completeness of manual data was between $37.5 \%$ and $52.1 \%$ [8] whilst this study results show $75.0 \%$ and $25.0 \%$.

The study revealed that there were defined key monitoring and evaluation and data management responsibilities at the hospital with a total score of 2.69 representing $89.7 \%$ score. Staffing needs and requirement assessment would be a first step in addressing staffing requirement for data generation and use of information for planning and decision-making. Callaghan, Ford and Schneider in 2010 and Mdege, Chindove and Ali in 2013 have all shown that task-shifting has been effective strategy for sharing of duties within the health care sector. The results from this study suggest that designating staff of monitoring and evaluation duties at the various facility levels to non-clinical staff such as data entry clerks or health information officers, could be a better way to improve the quality of data. This is backed by a study in Botswana, which pointed out that non-health workers had proper documentation for monitoring and evaluating programmes than health workers who were designated to do that [9]. A study from Malawi also confirmed that data entry clerks improved data quality at antiretroviral treatment clinics [10]. Thus, data quality is improved when there are dedicated staff for data collection and collation. A simple system of ensuring regular data quality checks may be very efficient and more reliable in the current monitoring and evaluation capabilities. The inadequate training programmes related to monitoring and evaluation at the tertiary level was identified in this study as a challenge [11].

Indicator definitions and reporting guidelines had a total score of 1.88 representing $62.7 \%$. Braa, Heywood, and Sahay study in Tanzania concluded that standadised templates has the potential to enhance the quality of data. The study found out that ownership of data-related tasks at facility levels was a key obstacle to data quality. Thus, facilitation materials are required for the use of data (12). Data use is seen as a very important part in improving the quality of data [13], [14]. The study revealed that data management processes were conducted in the facilities with a high score of 2.72 representing $90.7 \%$. Studies show that health professionals see data collection and collation as a very difficult task [15]. Nevertheless, results of this study show that health professionals created time to ensure proper data collection and collation were done.

Use of data for decision making also had a high score of 2.57 representing $85.7 \%$. The current study shows that use of data improves the quality of data. This was supported by Braa, Heywood, and Sahay's research which indicated that regular use of health data enhances the data quality since this brings out the discrepancies in the data as it is being used. Wagenaar et al. in 2015 also suggested that poor data quality is given as the main reason for poor use of routine health information. Thus, there is a link between data quality and use of data for decision making. When health information is not utilised during planning and decision making, then the whole purpose of data collection and collation and health information system is defeated and its relevance is lost [16]. Limited or lack of use generates a vicious cycle of inadequate demand of data and production of good quality information [16].

In addition to streamlining data-related duties with respect to staffing patterns, the study suggests some practical capacity development approaches to strengthen health information systems thereby improving demand and use of data as well as quality assurance. This include decentralizing training and coaching initiatives from district to facility-level for health workers delivering services at the facilities. This would allow for adequate support at the point of data generation. Ledikwe in 2013 revealed that on-the-job training and mentoring has been an effective method for strengthening monitoring and evaluation capacity and ensuring data quality within a national health system. Chaulagai in 2005 study also supports capacity building activities which are organised at the facility level. Dissemination of standardized materials for 
training and coaching/mentoring on health management information systems as well as job aids would help facilitate data quality.

\section{CONCLUSION}

In as much as hospitals are over stretched on limited resources making it difficult to invest in high technology such electronic medical records, there are low cost initiatives that can considerably and positively impact on newborn data management and quality. These include initiating health worker in-service training with respect to data collection and collation and mentoring on data quality in the various hospitals. Also, developing guidelines for data management and applying techniques that are effective to data management and reporting activities will ensure a strong health information system that will assure data quality.

\section{REFERENCES}

[1] Frenk. J., Chen. L., Bhutta. ZA., Cohen. J., Crisp. N., Evans. T., et al., "Health Professionals for a New Century: Ttransforming Education to Strengthen Health Systems in an Interdependent World," Lancet, 376(9756):1923-58, 2010.

[2] Whittaker. M., Hodge. N., Mares. RE., Rodney. A., "Preparing For The Data Revolution: Identifying Minimum Health Information Competencies Among The Health Workforce," Hum Resour Health [Internet], 13(1):17. Available from:http://human-resources health.biomedcentral.com/articles/10.1186/s12960-015-0002-x, 2015.

[3] Aqil. A., Lippeveld. T., Hozumi. D., "PRISM Framework: A Paradigm Shift For Designing, Strengthening And Evaluating Routine Health Information Systems," Health Policy Plan, 24(3):217-28, 2009.

[4] AbouZahr. C., Adjei. S., Kanchanachitra. C., From data to policy: good practices and cautionary tales. Lancet, 369(9566):1039-46, 2007.

[5] Makinde. OA., Mami. MI., Oweghoro. BM., Oyediran. KA., Mullen. S., "Investing In Health Information Management: The Right People, In The Right Place, At The Right Time," Heal Inf Manag J, 45(2):90-6, 2016.

[6] Asiimwe. AK., "Determinants of Effective Utilization of Routine Health," 2016.

[7] WHO. WHO technical consultation on newborn health indicators, 2014.

[8] Gimbel. S., Micek. M., Lambdin. B., Lara. J., Karagianis. M., Cuembelo. F., et al., "An Assessment of Routine Primary Care Health Information System Data Quality in Sofala Province, Mozambique," Popul Health Metr, 9, 2011.

[9] Ledikwe. JH., Kejelepula. M., Maupo. K., Sebetso. S., Thekiso. M., Smith. M., et al., "Evaluation of a WellEstablished Task-Shifting Initiative: The Lay Counselor Cadre in Botswana," PLoS ONE, 2013.

[10] Makombe. SD., Hochgesang. M., Jahn. A., Tweya. H., Hedt. B., Chuka. S., et al., "Assessing The Quality of Data Aggregated by Antiretroviral Treatment Clinics in Malawi," Bulletin of the World Health Organization, pp. 310-4, 2008.

[11] Ledikwe. JH., Grignon. J., Lebelonyane. R., Ludick. S., Matshediso. E., Sento. BW., et al., "Improving the Quality of Health Information: A Qualitative Assessment of Data Management and Reporting Systems in Botswana." Health Res Policy Syst, 12(1):7. Available from:

http://www.pubmedcentral.nih.gov/articlerender.fcgi?artid=3910237\&tool=pmcentrez\&rendertype=abstract, 2014.

[12] Chaulagai. CN., Moyo. CM., Koot. J., Moyo. HBM., Sambakunsi. TC., Khunga. FM., et al., "Design and Implementation of a Health Management Information System in Malawi: Issues, Innovations And Results," Health Policy Plan, 20(6):375-84, 2005.

[13] Braa. J., Heywood. A., Sahay. S., "Improving Quality and Use of Data Through Data-Use Workshops: Zanzibar, United Republic of Tanzania," Bull World Heal,90(5):379-84. Available from: http://www.pubmedcentral.nih.gov/articlerender.fcgi?artid=3341693\&tool=pmcentrez\&rendertype=abstract\%5Cnh ttp://www.scielosp.org/scielo.php?pid=S004296862012000500014\&script=sci_arttext\&tlng=es, 2012.

[14] Otwombe. KN., Wanyungu. J., Nduku. K., Taegtmeyer. M., "Improving National Data Collection Systems from Voluntary Counselling and Testing Centres in Kenya," Bull World Health Organ, 85(4):315-8.Availablefrom: http://www.pubmedcentral.nih.gov/articlerender.fcgi?artid=2636317\&tool=pmcentrez\&rendertype=abstract, 2007.

[15] Garrib. A., Stoops. N., McKenzie. A., Dlamini. L., Govender. T., Rohde. D., et al., "An Evaluation of the District Health Information System in Rural South Africa," South African Med J, 98(7):549-52. Available from: citeulikearticle-id:10728928\%5Cnhttp://imp-

primo.hosted.exlibrisgroup.com/openurl/44IMP/44IMP_services_page?sid=OVID\&isbn=\&issn=0256$9574 \&$ volume $=98 \&$ issue $=7 \&$ date $=2008 \&$ title $=$ South + African + Medical + Journal $\&$ atitle $=$ An + evaluation + of + the + Di strict+Health+Informat, 2008.

[16] Adejumo. A., "An Assessment of Data Quality in Routine Health Information Systems in Oyo State, Nigeria," 2017;(January):1-90. Available from: https://etd.uwc.ac.za/bitstream/handle/11394/5497/Adejumo_a_mph_chs_2017.pdf?sequence=1\&isAllowed=y, 2017. 